\title{
ARTÍCULOS
}

\section{REFLEXIONES EN TORNO A LAS FUENTES ORALES. HISTORIA Y MEMORIA EN LOS RELATOS SOBRE MIGRACIÓN ITALIANA EN ECUADOR (XIX-XX) ${ }^{1}$.}

\author{
Chiara Pagnotta \\ Universitat de Barcelona \\ chiara.pagnotta@ub.edu
}

\begin{abstract}
Resumen: Desde hace algunos años, en la comunidad académica, se afirmó la idea de que las fuentes orales ofrecen una interesante clave de lectura acerca de las interpretaciones, los sentidos y la relectura de los acontecimientos vividos por parte de sus protagonistas. Al mismo tiempo, se postuló que las fuentes orales están sujetas a una cierta forma de subjetividad y (auto) censura determinada por un control individual, colectivo o social sobre la fuente misma. En la parte inicial del texto, me propongo detallar las particularidades de las fuentes orales, en cuanto fuentes producidas a partir del encuentro entre investigador y testimonio del evento. En la segunda parte, pretendo ofrecer una reflexión acerca de la relación entre la historia y la trasmisión de la memoria, a partir de los relatos de los descendientes de los italianos que emigraron a Ecuador en el siglo XIX y finalmente me centraré en mostrar cómo algunos acontecimientos históricos son reelaborados, reinterpretados e inclusive olvidados por los protagonistas de la migración través del filtro de la memoria que cambia con el tiempo. Una fuente importante para este trabajo son los relatos de los inmigrantes italianos y sus descendientes recopilados en Ecuador entre 2010 y 2015.
\end{abstract}

Palabras clave: Fuentes orales, historia, memoria, Ecuador, Italia, Segunda Guerra Mundial.

Tittle: REFLECTIONS ON ORAL SOURCES. HISTORY AND MEMORY IN STORIES ABOUT ITALIAN MIGRATION IN ECUADOR $\left(19^{\text {TH }}-20^{\text {TH }}\right.$ CENTURIES).

Abstract: It is some years, inside the academic community, that it is emerged the idea that oral sources offer an interesting key about the interpretations, the feelings and the reworking of the lived events by their own protagonists. At the same time, it has been postulated that oral sources are subject to a certain form of subjectivity and (self) censorship, determined by individual, collective or social control over the source itself. In the initial part of the text, I propose to detail the particularities of oral sources, as the product of the encounter between the researcher and the witness of the event. In the second part, I intend to offer a reflection on the relationship between history and the transmission of memory, based on the stories of the Italians' descendants who emigrated to Ecuador in the 19th century. Finally, I will focus on showing how the filter of memory, that changes over time, re-elaborates, reinterprets and even forgot some historical events. An important source for this work are the stories of Italian immigrants and their descendants collected in Ecuador between 2010 and 2015.

\footnotetext{
${ }^{1}$ Una versión anterior y más corta de este trabajo fue presentada como ponencia oral en el Tercer Congreso de la Asociación Internacional AREIA "América Latina- Europa: Silencios, reticencias, ficciones en las narraciones de las migraciones y de los migrantes", 20-22 de abril de 2015, Ventimiglia (Italia).
}

Recibido: $15-07-2020$

Aceptado: $13-08-2020$

Cómo citar este artículo: PAGNOTTA, Chiara. Reflexiones en torno a las fuentes orales. Historia y memoria en los relatos sobre migración italiana en Ecuador (XIX-XX). Naveg@mérica. Revista electrónica editada por la Asociación Española de Americanistas [en línea]. 2020, n. 25. Disponible en: <http://revistas.um.es/navegamerica>. [Consulta: Fecha de consulta]. ISSN 1989-211X. 
Keywords: Oral sources, History, Memory, Ecuador, Italy, Second World War.

\section{Introducción}

Hace mucho tiempo me di cuenta de repente de que el país al que se pertenece no es, como dice la retórica habitual, al que se ama, sino del que uno se avergüenza. La vergüenza puede ser un vínculo más fuerte que el amor. Contrasté repetidamente mi descubrimiento con amigos de diversos países: todos reaccionaron de la misma manera, con sorpresa seguida inmediatamente de un acuerdo total, como si mi sugerencia fuera una verdad evidente. No estoy afirmando que la carga de la vergüenza sea siempre la misma; de hecho, varía enormemente de uno a otro país. Pero el vínculo de la vergüenza -la vergüenza como vínculo- siempre funciona para un número mayor o menor de individuos. [...] ¿Pero se puede someter al análisis histórico una pasión como la vergüenza? ${ }^{2}$

Es sabido que los investigadores se han interrogado a menudo acerca del papel que desempeñan las emociones en la narración histórica. Como señaló Barbara Rosenwein, el problema no concierne principalmente a las emociones mismas, ya que los seres humanos, tanto en el pasado como en el presente, siempre han vivido el miedo, la alegría, la tristeza, etc.; el interrogante se centra más bien en el papel que juegan estas emociones en la construcción del relato histórico y los efectos que crean en los demás ${ }^{3}$. Siguiendo este mismo enfoque, y conforme a lo afirmado por Lucien Febvre, las emociones no son simples reacciones automáticas a estímulos externos, sino que son contagiosas.

Ellas implican las relaciones de hombre a hombre, así como las relaciones colectivas. Estas nacen, sin duda, dentro de un fondo orgánico propio de cada individuo y, a menudo, en un acontecimiento que afecta a éste o que lo impacta gravemente con una violencia particular. Pero dichas emociones se muestran de una manera tal, que si queremos, su expresión es el resultado de una serie de experiencias de la vida en común, reacciones similares y simultáneas frente a situaciones idénticas y de contactos de la misma naturaleza; ellas son el fruto, si así lo queremos, de una fusión, de una reducción recíproca de diversas sensibilidades que rápidamente adquieren el poder de provocar entre todos los presentes, por una especie de contagio mimético, el complejo afectivo-motor correspondiente al acontecimiento ocurrido y padecido por un solo individuo ${ }^{4}$.

\footnotetext{
${ }^{2}$ GINZBURG Carlo. El vinculo de la vergüenza. New Left Review. Ene./feb. 2020, n. 120, pp. 39-48, pp. 39-40.

3 ROSENWEIN, Barbara. Worrying about Emotions in History. The American Historical Review. 2002, vol. 107, n. 3, pp. 821-841.

${ }^{4} \mathrm{Y}$ sigue así: "Así, poco a poco, las emociones que asocian a varios participantes -a su vez iniciadores y seguidores- han llegado a constituir un sistema de incentivos interindividuales que se han diversificado, según las situaciones y circunstancias, diversificando al mismo tiempo las reacciones y la sensibilidad de cada individuo. La simultaneidad así regulada de las reacciones emocionales es de tal naturaleza que confiere al grupo una mayor seguridad, o un mayor poder - la utilidad pronto se encontró justificando la constitución de un verdadero sistema de emociones. Ellos se convirtieron en una institución. Fueron regulados en la forma de un ritual. ¡Cuántas ceremonias entre pueblos primitivos son un conjunto de simulacros que tienen el objetivo evidente de despertar en todos, a través de las mismas actitudes y los mismos gestos, la misma emoción, fusionando a todos los individuos en una especie de individualidad superior, preparándolos para la misma acción!" FEBVRE, Lucian. Problemi di metodo storico. Torino: Einaudi, 1992, pp. 121-138, p.124. Publicación
} 
Lucien Febvre publicó estas líneas en 1941; no es difícil imaginar que el historiador hace una referencia implícita a las multitudes oceánicas reunidas por el partido nazi con motivo de sus celebraciones. En cualquier caso, estas reflexiones bien se adaptan a varios otros casos, ya que, en otras palabras, el recuerdo de lo vivido actuaría como un vector para la perpetración de un sistema de valores y creencias. Similar es el enfoque que utiliza Marc Bloch en Los reyes taumaturgos cuando califica como un error colectivo la creencia en la curación de la escrófula gracias al toque de los gobernantes franceses e ingleses. De particular relevancia para este ensayo es la creencia misma en el hecho de que el milagro haya acontecido. El perpetrarse de esta creencia en el tiempo podría explicarse gracias a los testimonios colectivos que se trasmiten de generación en generación ${ }^{5}$.

Llegamos entonces al primero de los elementos clave en nuestro discurso: el testimonio oral trasmitido a través del tiempo histórico y su fiabilidad. Por varios autores se ha puesto de relieve cómo lo que un individuo recuerda depende de lo que ha sido discutido y reelaborado en intercambios con otros. Es decir, la sociedad y el grupo de pertenencia participan de la formación de la memoria individual y, al revés y en consecuencia de lo dicho, en las memorias individuales se encuentran trazas de las representaciones sociales colectivas ${ }^{6}$.

Lo que se recuerda y quién lo hace es uno de los núcleos del trabajo del filósofo Paul Ricoeur. Entre otros aportes al tema, el autor postula primeramente una estrecha relación entre memoria y procesos identitarios, y segundo, que la memoria es a menudo movilizada (y abusada) por reivindicar la identidad ${ }^{7}$. Se desprenden interrogantes relacionados con la memoria y la imaginación de una identidad atemporal inmutable en el tiempo que coincidirían precisamente con el abuso de memoria y, del mismo modo, el abuso del olvido ${ }^{8}$. Finalmente, ya Philippe Joutard alertaba hace tiempo de que la memoria no se caracteriza por conservarse siempre igual a sí misma, más bien se encuentra en constante reelaboración bajo el efecto de los acontecimientos del presente ${ }^{9}$. Ponía de relieve, además, que en un testimonio oral "la ausencia es igual de significativa que la presencia [...] La

original en francés: La sensibilité et l'histoire. Comment reconstituer la vie affective d'autrefois. Annales HSS. Janv.-juin. 1941, n. 1-2, pp. 5-20. Agradezco a la Dra. Malena Bedoya la traducción de las líneas del texto de Febvre, que creo inédito en castellano.

${ }^{5} \mathrm{Al}$ respecto véase también BLOCH, Marc. La guerra e le false notizie. Roma: Donzelli, 2004. [Títulos originales en francés: Souvenirs de guerre 1914-1915 y Réflexions d'un historien sur les fauses nouvelles de la guerre].

6 Sobre la memoria como proceso social colectivo véase ASSMAN, Jan. La memoria culturale. Scrittura, ricordo e identità politica nelle grandi civiltà antiche. Torino: Giulio Einaudi editore, 1992. [Título original en alemán: Das kulturelle Gedächtnis. Schrift, Erinnerung und politische Identität in frühen Hochkulturen. München: C. H. Beck'sche Verlagsbuchhandlung, 1992]; HALBAWCHS, Maurice. Los marcos sociales de la memoria. Barcelona: Anthropos Editorial, 2004. [Original en francés: Les cadres sociaux de la mémoire. París: Félix Alcan, 1925].

7 RICOEUR, Paul. La memoria, la historia el olvido. Buenos Aires: Fondo de Cultura Económica de Argentina, 2000, pp. 109-113. [Original en francés: La mémoire, I'histoire, l'oubli. Paris: Editions de Seuil, 2000]. Desde la disciplina histórica, Luisa Passerini se ha interrogado acerca de la relación entre subjetividad, identidad y memoria. PASSERINI, Luisa. Storia e soggettività. Le fonti orali, la memoria. Firenze: la Nuova Italia Editrice, 1988.

${ }^{8}$ RICOEUR, Paul. La memoria, la historia el olvido. Op. cit. pp. 109-113.

9 JOUTARD, Philippe. Le voci del passato. Torino: SEI, 1987, p.17. [Original en francés: Ces voix qui nous viennent de passè. París: Hachette, 1983]. 
memorización, como el olvido son procesos activos, no es posible interpretar el olvido como una debilidad y la memoria como una simple reproducción de la realidad del pasado" ${ }^{\prime 10}$.

Precisamente en este punto se centran mis reflexiones acerca de las relaciones y las influencias reciprocas entre historia y memoria de las migraciones italianas en Ecuador que son deudoras de las historias de vida de unos cuantos inmigrantes, recopiladas a comienzos del siglo XXI. En este texto se trata de poner de relieve algunos elementos de los testimonios de los descendentes de los inmigrantes y de analizar los testimonios de dos protagonistas de la migración, que ofrecen, a través del relato, una clave de interpretación de la vida cotidiana y de las creencias de un determinado grupo social, en un particular momento histórico ${ }^{11}$. En el segundo de los casos, me dedicaré en particular a estudiar las narraciones que abarcan la temporalidad de la Segunda Guerra Mundial para llegar a mostrar cómo ciertos acontecimientos son omitidos por los testigos y otros mal localizados, todo ello de acuerdo con la historia actual y la legitimidad política que estos acontecimientos tienen dentro de la historia del grupo al que pertenecen. No es anodino recordar que historia y memoria son "arenas de disputas del poder" ${ }^{12}$ y que los relatos que surgen de ambas se estructuran según variables de clase, etnicidad, género y nación ${ }^{13}$. En la elaboración del pasado de la historia contemporánea de Italia, el gran acontecimiento de disputa que moviliza emociones, con el que las generaciones que lo vivieron y las posteriores se confrontan ineludiblemente, es la experiencia del fascismo, su epílogo en la Segunda Guerra Mundial, las leyes raciales y finalmente la experiencia de la Resistenza, con su carácter de guerra de liberación de las tropas nazifascistas y a la vez guerra civil entre italianos y guerra de clase y revolucionaria ${ }^{14}$. Esta historia común puede derivar en interpretaciones divergentes de los hechos y, por ende, en memorias divididas, que caracterizan en diferentes grados, tanto a los italianos que viven en el suelo patrio como a aquellos que han inmigrado y sus descendientes.

Estas reflexiones mías son deudoras de un libro de Alessandro Portelli, que ha marcado mis reflexiones como investigadora y como ciudadana italiana que ha utilizado las fuentes orales: L'ordine è già stato eseguito. Roma, le Fosse Ardeatine, la memoria ${ }^{15}$. En el libro, el autor recupera el significado de esta masacre de 335

\footnotetext{
${ }^{10}$ JOUTARD, Philippe. Le voci del passato... Op. cit., p. 200.

${ }^{11}$ Entre otros, acerca de la importancia del estudio de las narraciones individuales para reconstruir lo que los individuos insertados en un proceso histórico han "hecho, pensado y construido" véase el trabajo de Adriano Prosperi sobre las escrituras autobiográficas de los jesuitas. PROSPERI, Adriano. La vocazione. Storie di gesuiti tra Cinquecento e Seicento: Torino: Einaudi, 2016, p. XVI.

${ }^{12}$ BUSTOS, Guillermo. La irrupción del testimonio en América Latina: intersecciones entre historia y memoria. Presentación del dossier: Memoria, historia y testimonio en América Latina. Historia Critica. Ene./abr. 2010, n. 40, pp. 10-19, p. 13

${ }^{13}$ BUSTOS, Guillermo. La irrupción del testimonio en América Latina... Op. cit.

${ }^{14} \mathrm{La}$ interpretación de la Resistencia como conflicto que presenta estos tres aspectos ha tardado mucho en afirmarse, y la historiografía más tradicional y oficial del evento está orientada a destacar únicamente el carácter patriótico de guerra de liberación del invasor nazi. Acerca de la renovación historiográfica véase: PAVONE, Claudio. Una guerra civile. Saggio storico sulla moralità nella resistenza. Torino: Bollati Boringhieri, 1994.

${ }^{15}$ PORTELLI, Alessandro. La orden ya fue ejecutada. México: Fondo de Cultura Económica, 2003. [Original en italiano: L'ordine è già stato eseguito. Roma, le Fosse Ardeatine, la memoria. Roma: Donzelli, 1999].
} 
personas llevada a cabo en las cercanías de Roma por las tropas nazis en represalia de una acción partisana acontecida el día antes en la capital. En 1999, Portelli desvela la historia y las memorias no coincidentes que existían en aquel entonces acerca del evento. Unas cuantas operaciones políticas de los últimos años habían facilitado la equiparación entre todos los muertos italianos, ya fueran partisanos o repubblichini ${ }^{16}$, y alimentaron el caldo de cultivo en el que se afirmó una narración falsa y a la vez hegemónica del acontecimiento ${ }^{17}$.

Si no hay duda de que las narraciones son representaciones sociales, gracias a un minucioso trabajo sobre las fuentes, sobre su cruce, acerca de lo que Carlo Ginzburg identifica como la prueba, es posible destacar la distancia (o lejanía) entre los testimonios y la realidad que dibujan ${ }^{18}$. Se trata aquí de tratar de entender qué impulsa a nuestros testigos a producir ciertos testimonios y por qué se propagan. Diversos autores han puesto en relieve que las narraciones son un vehículo de deseos y temores que expresa el testigo, aunque de manera inconsciente. A este propósito afirma Traverso que "el pasado se trasforma en memoria colectiva después de haber sido seleccionado y reinterpretado según las sensibilidades culturales, los dilemas éticos y las conveniencias políticas del presente" ${ }^{19}$. En esto precisamente radica la importancia y la particularidad de las fuentes orales, es decir, en la recuperación de lo vivido conforme a cómo ha sido asumido y reelaborado por los protagonistas/testimonios. Por ende, estudiar estas narraciones ayudaría a la comprensión del presente y del pasado.

Por lo dicho, resulta de interés entender por qué ciertas narrativas alrededor de la inmigración italiana en Ecuador se forman y se propagan en un momento histórico determinado. Las fuentes principales utilizadas para este ensayo son los relatos recopilados por mí en Ecuador entre 2010 y 2015, en el seno del grupo italiano en el país andino. Se trata de varias narraciones de descendientes de inmigrantes, y, de particular importancia, de los testimonios de dos mujeres de ascendencia italiana que han vivido gran parte de su vida en Ecuador ${ }^{20}$. Debido al necesario cuidado en

\footnotetext{
${ }^{16}$ La Repubblica Sociale Italiana fue el régimen liderado por Mussolini vigente entre septiembre de 1943 y abril de 1945. Abarcaba los territorios del norte y parte del centro de Italia. En el mismo periodo en el centro norte de la península actuaban los partisanos y desde el sur se estaba verificando el avance de los Aliados.

17 Se tiende a culpabilizar a los partisanos por no haberse presentado para responsabilizarse de la acción que había llevado a la muerte a 33 soldados alemanes, y, de ahí, la posterior represalia y matanza de las Ardeatine. Esto nos dice la memoria de unos cuantos testigos en 1999, mientras la historia nos dice que el orden de la represalia fue ejecutado sin aviso previo (de ahí deriva el título del libro de Portelli).

${ }^{18}$ Acerca de la importancia de la prueba en la investigación histórica y judicial, véase: GINZBURG, Carlo. Il giudice e lo storico. Considerazioni in margine al processo Sofri. Milano: Feltrinelli, 2006. [Versión en español: El juez y el historiador. Consideraciones al margen del proceso Sofri. Madrid: Anaya \& Mario Muchnik, 1993].

19 TRAVERSO, Enzo. El pasado. Instrucciones de uso. Historia, memoria, política. Madrid; Barcelona: Marcial Pons; Ediciones Jurídicas y Sociales, S.A., 2007, p. 14.

20 Estas han sido recopiladas en el marco de investigaciones acerca de la inmigración italiana en Ecuador cuyos resultados más avanzados se encuentran principalmente en PAGNOTTA, Chiara. Situando los márgenes de la nación. Los italianos en Ecuador (XIX-XX). Quito: Abya-Yala; TEIAA, 2016. Cabe matizar que en aquellas investigaciones la utilización de las fuentes orales fue sido marginal. Además, el tema específico de este articulo ha sido solo una parte de las historias de vida de las dos testigos. Sobre el papel de las mujeres como narradoras de la vida cotidiana y familiar,
} 
el tratar algunos temas sensibles en la vida de los testimonios, se ha decidido utilizar apodos y cambiar algunos detalles personales, pues en esta investigación el testimonio no es importante en sí, sino más bien en cuanto expresión de la mentalidad del grupo social de pertenencia.

En la primera parte del texto, presentaré unas cuantas consideraciones acerca de las fuentes orales, su producción, utilización y conservación. Luego, trabajaré dichos contenidos a partir de las reflexiones surgida durante mis trabajos de campo en Ecuador acerca de la trasmisión de la memoria entre los descendientes de inmigrantes y, en la última parte, me centraré en mostrar cercanías y distancias entre las historias y las memorias de dos mujeres protagonistas de los acontecimientos estudiados. Finalizo con algunas consideraciones de carácter general.

\section{De archivos y fuentes orales}

Antes que nada, hay que entender qué es una fuente. Según el diccionario de la Real Academia Española, una fuente es una "persona o cosa que proporciona información (octavo significado)"21. Cabe destacar que el concepto de fuente evoluciona con el tiempo, llegándose a distinguir entre fuentes escritas, orales, visuales, etc. No hay una definición clara y aceptada universalmente de lo que es específicamente una fuente oral. Ya en 1993 Giovanni Contini afirmaba que "el de las fuentes orales puede parecer un simple problema de archivo. Se trataría de nuevas fuentes, registradas en un soporte inusual, que deben ser tratadas adecuadamente" 22 . En su definición técnica se trataría de una fuente registrada (en la mayoría de los casos) cuyo soporte no es el papel ${ }^{23}$.

En base a los interrogantes de cada investigación, cada estudioso construye su proprio archivo oral -donde conserva estas fuentes-, que puede ser de carácter privado o público ${ }^{24}$. El tema del almacenamiento y conservación de las fuentes orales pone de relieve una de las diferencias principales entre las fuentes orales y las más tradicionales, las escritas; a saber, que las primeras tienen que ser producidas para poder ser estudiadas y son el resultado del encuentro entre el investigador que indagada acerca de un determinado acontecimiento y el testigo (o informante) del mismo. En una fase posterior, después de su producción, las fuentes orales eventualmente pueden ser depositadas y luego ser consultables y utilizables para los demás interesados ${ }^{25}$.

véase en español PAGNOTTA, Chiara. La migración ecuatoriana e España e Italia. Historias, memorias e identidades 1995-2007. Quito: Universidad Andina Simón Bolívar; Corporación Editora Nacional, 2014, p. 16.

${ }_{21}$ [Consulta: 26-04-2020]. Disponible en $<$ https://dle.rae.es/fuente $>$.

22 CONTINI, Giovanni y MARTINI, Alfredo. Verba manent. L'uso delle fonti orali per la storia contemporanea. Roma: La Nuova italia Scienifica, 1993, pp. 11.

${ }^{23}$ Aunque la actividad de trascripción de la fuente determina el paso de la oralidad a la escritura para que la fuente pueda ser leída.

${ }^{24}$ PASSERINI, Luisa. Conoscenza storica e storia orale. Sull'utilità e il danno delle fonti orali per la storia. En: PASSERINI, Luisa (coord.). Storia orale: vita quotidiana e cultura materiale delle classi subalterne. Torino: Rosenberg \& Sellier, 1978, pp. VII-XLIII, p. XVI.

${ }^{25}$ Se destaca la experiencia del archivo AREIA audioarchivio delle migrazioni tra Europa e America Latina ubicado en la Universidad de Génova (Italia) y fundado en 2007 por la profesora Chiara Vangelista. 
Por lo dicho, es evidente que la fuente oral se produce en el encuentro entre dos sujetos, ambos portadores de identidades, edades, géneros, visiones del mundo, entre otras características diferenciales, y esta diversidad se refleja en la producción misma de la fuente. A este propósito, Chiara Vangelista destaca que la subjetividad que emerge de los relatos se manifiesta bajo el estímulo de una situación que es única en el momento en el que se produce y que influye en las formas de la narración, en las invenciones y en las censuras que cada testimonio practica al relatar su propia historia ${ }^{26}$.

De ello derivan algunas consideraciones. En primer lugar, la fuente oral no es la voz de los grupos subalternos ${ }^{27}$. Por un tiempo bastante dilatado, la narración histórica construida a través de la utilización de las fuentes orales ha sido imaginada como el instrumento para dar voz a aquellos que carecían de ella. Aunque es indudable el aporte que el trabajo con las fuentes orales ha significado para la comprensión de la historia de los individuos y de los grupos que poco espacio tenían en la Historia construida alrededor de los grandes personajes, lo cierto es que, en años más recientes, varios estudiosos se han alejado de tal enfoque, llegando en último término a utilizar las fuentes orales como método para entender las creencias de un grupo social ${ }^{28}$.

Tal afirmación conduce inmediatamente a otras. El investigador no es neutro en el proceso de construcción de la fuente oral. Varios historiadores han hecho hincapié en la unicidad del momento en el que se produce la fuente oral, $y$, por ende, en la unicidad de la fuente oral. Se ha puesto de relieve que dos narraciones por parte de un mismo testimonio no serán nunca relatadas de manera idéntica frente a dos investigadores distintos y en dos momentos históricos diferentes. Un segundo relato de un acontecimiento no sería el mismo a 10 años (por ejemplo) de distancia del primero, pues las percepciones y las interpretaciones varían con el tiempo.

Cada vez es más frecuente que el historiador se sitúe respecto al acontecimiento estudiado. A menudo, en los libros de historia (y no únicamente de quienes trabajan con las fuentes orales) aparecen breves biografías del autor. Ello se basa en el convencimiento de que los intereses de investigación y las interpretaciones de los acontecimientos estudiados dependen también de las experiencias vividas por quien los estudia. Por ende, con la explicación biográfica, se trataría más bien de ofrecer al lector las claves para entender cómo y por qué un determinado acontecimiento ha sido interpretado de una u otra manera por un determinado investigador ${ }^{29}$.

\footnotetext{
${ }^{26}$ VANGELISTA, Chiara. Da fala á história: notas em torno da legitimidade da fonte oral. En: HERCULANO LOPES, Antonio; PIMIENTA VELLOSO, Monica y JATAHY PESAVENTO, Sandra (orgs.). História e linguagens. Texto, imagem, oralidade e representaçoes. Rio de Janeiro: 7Letras, 2006, pp. 185-193, p. 188.

${ }^{27}$ Hacemos aquí referencia a los grupos subalternos en términos gramscianos, diferenciándolos del grupo hegemónico también en el campo de la producción cultural.

${ }^{28}$ Véase en particular PASSERINI, Luisa (coord.). Storia orale. Op. cit. y PASSERINI, Luisa. Storia e soggettività. Op. cit.

29 Por ejemplo, véase NOIRIEL, Gérard. Penser avec, penser contre. Itinéraire d'un historien. París: Éditions BELIN, 2003, pp. 249-278 (Postface. Un désir de vérité).
} 
Dicho esto, es adecuado poner de relieve que trazas de las fuentes orales se encuentran a menudo entre las escritas. Cabe mencionar el ensayo de Ginzburg $L_{\text {'inquisitore come antropologo }}^{30}$, en el que el historiador pone de relieve que a menudo los archivos se componen de trascripciones escritas de testimonios orales. Haciendo referencia a otro trabajo de Ginzburg, cabe agregar que también los expedientes escritos de los procesos inquisitoriales que tuvo que enfrentar Menocchio tienen como importante fuente lo relatado oralmente por el molinero ${ }^{31}$. Corresponde matizar además que también las varias fuentes inquisitoriales podrían estar parcialmente sujetas a las condiciones que las producen, pues, es conocido el repertorio de presiones ejercidas por los inquisidores para que los inquiridos confirmaran lo que los primeros ya presuponían como verdadero.

\section{De la trasmisión de la memoria y la representación del pasado}

Por varias partes se ha puesto de relieve que en Europa el surgimiento del testigo como protagonista de la historia reciente se aceleró como consecuencia del horror de los campos de exterminio ${ }^{32}$. Se ha afirmado el deber de la memoria por parte de los sobrevivientes del Holocausto que se concreta en narrar la experiencia del campo para que lo acontecido no vuelva a ocurrir. ${ }^{33}$ Cabe tener presente al respecto que, en España, un pionero en este campo fue Ronald Fraser con su historia oral de la guerra civil. ${ }^{34}$

Por lo que respecta al continente americano, también la visibilidad del testimonio en la escena pública es algo bastante reciente que se desarrolla después de las dictaduras cívico-militares que se instalaron en el área. Aunque en diferentes latitudes, dos títulos emblemáticos son de 1965, la Autobiografía de Malcolm X, y de 1983, Me llamo Rigoberta Menchú ${ }^{35}$.

Varios autores han enfatizado cómo las experiencias de guerra sean un argumento importante en las investigaciones con las fuentes orales ${ }^{36}$. Ahora bien,

\footnotetext{
${ }^{30}$ GINZBURG, Carlo. Il filo e le tracce: vero, falso, finto. Milano: Feltrinelli, 2006, pp. 270-280. [Trad. en español: El hilo y las huellas: Lo verdadero, lo falso, lo ficticio. Buenos Aires: Fondo de Cultura Economica, 2010].

${ }^{31}$ GINZBURG, Carlo. II formaggio e i vermi. II cosmo di un mugnaio del '500. Torino: Einaudi, 1976. [Trad. en español: El queso y los gusanos. El cosmos, según un molinero del siglo XVI. Barcelona: Muchnik Editores, S.A., 1981].

32 WIEVIORKA, Annette. L'era del testimone. Milano: Raffaello Cortina Editore, 1999. [Original en francés: L'Ėre de témoin. París: Plon, 1998]. He traducido el francés témoin como testigo en español. Otros estudiosos han preferido traducirlo con testimonio. En mi opinión, el matiz con el que Wieviorka utiliza el término se refiere a la persona que da testimonio acerca de algo, y por ello testigo.

${ }^{33}$ Véase LEVI, Primo. Se questo è un uomo. Torino: De Silva, 1947; LEVI, Primo. I sommersi e i salvati. Torino: Einaudi, 1986.

${ }^{34}$ FRASER, Ronald. Blood of Spain. New York: Pantheon Books, 1979. [Versión en español: Recuérdalo tú y recuérdalo a otros. Barcelona: Editorial Critica, 1979]. Cabe destacar, en años más recientes, los debates y los avances que se han desarrollado en torno a la revista Historia, Antropología y Fuentes Orales.

${ }^{35}$ X, Malcolm y HALEY, Alex. The autobiography of Malcolm X. New York: Grove Press, Inc., 1965 y BURGOS, Elizabeth (con MENCHÚ, Rigoberta). Me llamo Rigoberta Menchú y así me nació la conciencia. La Habana: Casa de las Américas, 1983.

${ }^{36}$ Entre otros véase PORTELLI, Alessandro. Racconti di cura, racconti di guerra. La legittimità della narrazione. Genesis. Rivista della società italiana delle storiche. 2002, vol. I, n. 1, pp. 254-259.
} 
parece que las experiencias violentas y traumáticas en diferentes conflictos del siglo XX han provocado también una multiplicación de las memorias por parte de los protagonistas de aquellos acontecimientos. Cabe agregar que también las experiencias de la inmigración y la trasmisión de su memoria podrían interpretarse como acontecimientos, a veces traumáticos, que han ocurrido en la esfera pública y que causaron una multiplicación de las memorias.

Cabe subrayar algunos elementos que conciernen a las narraciones actuales de los descendientes de los inmigrantes italianos en Ecuador. Conforme a lo destacado en otras investigaciones sobre la trasmisión de la memoria a las generaciones posteriores que no han vivido la experiencia del traslado de un continente a otro ${ }^{37}$, se asiste a una importante producción de libros familiares, de estilo genealógico, acerca de la experiencia de los antepasados migrantes. En los volúmenes que se han podido consultar se destacan un par de fotografías del ancestro, fecha y lugar de nacimiento, fecha y lugar de la muerte, principales (pocos) detalles biográficos y algunas líneas sobre los principales acontecimientos de su vida, nada más. Por lo tanto, la historia de la migración familiar aparece, en realidad, representada por sólo unas pocas fechas. A nuestro parecer, la trasmisión de la memoria en el marco del núcleo doméstico había sido parcial, pues los autores de dichos libros realmente sabían poco acerca de la vida real de sus progenitores. Este era el caso en particular de aquellos cuyos antepasados habían emigrado de Italia en el siglo XIX, remontándose a una experiencia más antigua en el tiempo. Trabajando en profundidad con las fuentes, se observa que, a menudo, y de manera no voluntaria, se presentaban como propias experiencias leídas en los libros sobre migración, llegando así a perpetrar una imagen inmóvil de lo que había sido la experiencia de la inmigración italiana en Ecuador. Es útil recordar que en aquellos libros familiares de migración y en las pocas memorias recuperadas, la mayoría de los pioneros representados eran varones. En todo caso, el punto en común de todas estas narraciones era que los antepasados italianos eran todos brava gente, infaticabili lavoratori.

Conocemos, desde hace ya algún tiempo, el vínculo, ciertamente engañoso, entre la inmigración y el crimen en los países de llegada, que tanto espacio tiene en los debates actuales y ha tenido en el pasado a lo largo de la historia de la inmigración italiana en el siglo $\mathrm{XIX}^{38}$. Las imágenes del italiano rápido con el cuchillo como en Argentina, o peligroso anarquista en Estados Unidos, regicida en Francia no se abre espacio en ninguna de las narraciones. Por supuesto, no es que tenga

37 En particular, se hace referencia a una beca de postdoctorado disfrutada por la autora y otorgada en 2013 por el Programa Nacional de Pós-Doutorado de Capes (PNPD- Capes). El post-doctorado se ha desarrollado en el Programa de Pós-Graduação em História, de la Universidade do Estado de Santa Catarina (PPGH-Udesc), Laboratório de Relações de Género e Família (LabGeF), Florianópolis bajo la supervisión de la profesora Glaucia Olivera de Assis. Los primeros resultados de aquella investigación han sido publicados en PAGNOTTA, Chiara y OLIVEIRA DE ASSIS, Glaucia. Os italianos no espaço público de Santa Catarina (Brasil). Entre epopeia e festas étnicas. Confluenze [em línea]. 2017, vol. 9, n. 1, pp. 78-106. Disponible en $<$ https://confluenze.unibo.it/article/view/7078/6805>.

38 Véase por el caso argentino SCARZANELLA, Eugenia. Italiani malagente. Immigrazione, criminalità, razzismo in Argentina, 1890-1940. Milano: Franco Angeli, 1999. [En español: Ni gringos ni indios. inmigración, criminalidad y racismo en Argentina. Buenos Aires: Universidad de Quilmes, 2002]. 
que aparecer obligatoriamente; lo raro, es que no aparezca ninguna fisura en la imagen de exaltación del antepasado como buen y honesto trabajador, buen pater familias.

En el caso ecuatoriano, sabemos cómo, coexisten un par de imágenes de los inmigrantes italianos que estuvieron vigentes en el siglo XIX y llegaron a abarcar las primeras décadas del siglo XX. Por un lado, los inmigrantes italianos eran considerados como un elemento de civilización por el país, mientras que, por otro lado, eran considerados como trabajadores demasiado exigentes por parte de los propietarios ecuatorianos que preferían seguir empleando mano de obra local con el método del concertaje. En el peor de los casos, fueron considerados por las élites como peligrosos portadores de ideologías exóticas y degenerativas ajenas al contexto andino, primero el socialismo y el anarquismo y, más tarde, ya en el siglo $\mathrm{XX}$, el fascismo ${ }^{39}$.

Este matiz de la inmigración italiana no aparece en los relatos de los testimonios familiares, ni para expresar una valoración, ya sea positiva o negativa, ni para hablar de la mirada del país andino hacia la inmigración. Esto deja abierta la puerta a pensar en una omisión de algunos aspectos de la historia del grupo que se pretende ocultar o que, tal vez, con el paso del tiempo se han olvidado ${ }^{40}$. A este propósito, es preciso recalcar la evidente tendencia a ocultar las partes más íntimas (o vivida como problemática) de la propia historia en la narración frente a otra persona que es, al fin y al cabo, una desconocida. De otro lado, es cierta la importancia de la relación de cercanía y complicidad entre testimonio e investigador dada por el factor de la italianidad que hacía fluir la comunicación. De hecho, los testimonios expresaban la importancia de ser confirmados por mi - en cuanto representante (involuntaria) de la italianidad y del saber universitario- como testigos fiables acerca de la inmigración italiana en Ecuador ${ }^{41}$.

Eran de naturaleza diferente las confidencias que se hacían al apagar la grabadora, las alusiones, las frases dejadas a medias, que mostraban un mundo no representado en el espacio público. Estas tipologías de conversaciones se mantenían en el espacio no-oficial del diálogo y también trataban temas políticamente incorrectos en los que, entre otras cuestiones, emergía la tendencia a la endogamia de los italianos. En otros casos, se llegó a hablar de la preferencia de unas cuantas familias porque sus hijas permanecieran solteras o se ordenaran monjas en lugar de unirse a los locales. En definitiva, parece que lo que surgió cuando la entrevista se consideró terminada por los testigos fue el espacio privado de la memoria, que no coincidía con la imagen pública de la inmigración italiana.

\footnotetext{
${ }^{39}$ Estos temas son ampliamente tratados en PAGNOTTA, Chiara. Situando los márgenes de la nación. Op. cit.

${ }^{40}$ Es una tesis clásica la de Ernst Renan sobre cómo una nación se basa en recuerdos compartidos, olvidos y errores históricos. A menudo su análisis se ha utilizado para explicar no únicamente un paradigma nacional, más bien se ha aplicado también a diferentes formas de agrupación identitarias de tipo étnico. RENAN, Ernst. Qu'est-ce qu'une nation? En : FOREST, Philippe (dir.). Qu'est-ce qu'une nation? Lit-térature et identité nationale de 1871 à 1914. París: Pierre Bordas et fils, Éditeur, 1991, pp. 12-48.

${ }^{41}$ Un informante llega a afirmar: "No pierdas el tiempo [hablando con otros testigos]. El único archivo de la inmigración italiana soy yo". 2015, 11 de marzo, Cuenca (Ecuador). Archivo personal de la autora. Testigo anónimo.
} 


\section{Narrar la vida de los/las inmigrantes}

El hijo conductor de las narraciones acerca de la inmigración italiana parece ser la bondad de los italianos que forma parte del imaginario trasmitido por los descendientes de los primeros inmigrantes, y por los protagonistas de estas narraciones en el siglo XX.

En el relato autobiográfico, al lado de la narración de los hechos emerge una autopresentación pública por la que, al tiempo que presentan los acontecimientos, los narradores se presentan a sí mismos dentro de estos. Hoy en día es una evidencia reconocida por muchos historiadores que todos aprendemos y conocemos la historia a partir de nuestra propia historia, familiar o personal, y, por lo tanto, como descendientes de italianos en Ecuador o inmigrantes italianos en Ecuador, hablar de la propia historia significa también hablar de la historia reciente, de cómo se vivió y cuáles fueron sus consecuencias en la vida de los protagonistas que han vivido el acontecimiento.

Se ha visto cómo, en el siglo XX, la supuesta peligrosidad de los inmigrantes italianos deriva de la ideología totalitaria del país de origen. ${ }^{42} \mathrm{He}$ localizado algunos testigos directos de los acontecimientos que tuvieron lugar en coincidencia con la segunda guerra mundial y pretendo aquí mostrar dos narraciones en particular, y sus silencios, que contribuyen a crear un imaginario acerca de la inmigración italiana en el país andino.

En esta parte del trabajo utilizaré dos historias de vida de dos testigos de la época, dos jóvenes mujeres en la década de 1940. Nerea es una mujer que dejó Italia, siguiendo a su familia para escapar de las leyes raciales, mientras que Rocío es descendiente de italianos que llegaron a mediados del siglo XIX. Estos testimonios destacan como vehículo de transmisión de deseos y miedos inextricablemente mezclados con la vida real.

Para Nerea, el temor estaba representado por la fuga de Italia hacia un mundo desconocido debido a las leyes raciales, porque "o lasci la terra o ci lasci la pelle" es decir o dejaba la tierra o se dejaba la piel ${ }^{43}$. Según las palabras de la testigo:

Nosotros nos estábamos preparando para ir a la escuela. Era por la mañana temprano y alguien toca el timbre. $Y$ abro la puerta y se presentan dos hombrecitos - pues eran dos hombres diminutos- y dicen: "OVRA". OVRA es la policía política. Preguntan por mi padre, lo ven y se lo llevan. Se lo han llevado con ellos y les han requisado los pasaportes. Nosotros habíamos previsto embarcarnos con el Orazio. Bueno, en fin, el hecho que estos señores nos secuestrasen los pasaportes nos salvó la vida ${ }^{44}[\ldots]$.

El primer día hemos pasado por [el puerto de] Barcelona. Era día de corrida. El recuerdo de las personas vestidas de negro por la guerra. El puerto con los barcos

\footnotetext{
42 Véase en particular ESTRADA, Jenny. II Guerra Mundial. Lista negra en Ecuador. Guayaquil: Poligrafía C.A., 2006 y PAGNOTTA, Chiara. Situando los márgenes de la nación. Op. cit.

43 2012, 06 de mayo. Guayaquil (Ecuador). Archivo personal de la autora. Nerea.

${ }^{44}$ El buque Orazio parte de Génova en enero de 1940 rumbo a Valparaíso. Durante la navegación, en altamar a lo largo de Toulon sufre de un incendio. Hubo más de cien víctimas. La ruta que cumplía el Orazio en aquel entonces era seguida como vía de escape por varios judíos europeos.
} 
hundidos, esto era terrible. Viajábamos solo de noche, con las luces de la máquina a vapor apagadas porque, aunque aún Italia no había entrado en guerra, podía pasar cualquier cosa ${ }^{45}$. Cuando llegamos al Atlántico, ya ahí había luz y se podía viajar tranquilamente. Nosotros viajábamos en el buque Conte Biancamano. En Génova se ha embarcado también gente que estaba viajando en el Orazio que ha padecido un incendio. Ellos tenían unos la pierna rota, otros el brazo quemado. Ha sido una sensación fea.

ChP: ¿Por qué Ecuador y no otro lugar?

Mi padre había pedido la autorización para ir a Ecuador, Argentina y Venezuela. Ya que el tiempo corre, se había decidido que el primer visado que llagara, pues para aquel país se iba a ir ${ }^{46}$.

El miedo hacia los desconocidos parece atenuarse una vez llegados a Ecuador, la joven (en aquella época) testimonio afirma más bien que se acostumbró rápidamente a la vida cultural del país. Las condiciones fueron endureciéndose, según la testigo, particularmente después del alineamiento de Ecuador con la doctrina de la Defensa Continental, y las consiguientes medidas que incluían la adopción de las listas negras primero inglesa y luego estadunidense, que supusieron la intervención en contra de los bienes y propiedades de los súbditos de los países del Eje residentes en Latinoamérica e identificados como fieles económicamente y políticamente a los países de origen. También se procedió al establecimiento de algunas bases militares estadounidenses en territorio ecuatoriano. Cabe subrayar que las empresas que aparecían en las listas negras (Proclaimed List of Certain Blocked Nationals) se venían actualizando periódicamente. Por lo que concierne a Estados Unidos, tales empresas no podían comerciar con el país, hecho que supuso el quiebre de muchas de ellas ${ }^{47}$. Volviendo a lo contado por Nerea:

Luego, durante la guerra, llegaron los americanos [estadounidenses], destruyeron todo lo que había y se convirtieron en los amos. Los italianos fueron maltratados porque, aunque no fuéramos fascistas, éramos italianos. Fue desagradable. Así que primero viajamos en avión, luego llegaron los americanos y tuvimos que ir en tren. Ya no podíamos tomar un avión porque había una base militar en Salinas, y era la mejor playa para ir, así que... Todos los que estaban en la lista negra no podían subir a un avión. Italianos y alemanes.

Los americanos habían venido aquí e hicieron todo tipo de cosas. A los italianos los trataron mal, a los italianos y a los alemanes. Prohibición del avión, prohibición de hacer esto, confiscación de todos los bienes. No podías trabajar, las mujeres que estaban casadas con los italianos... También hemos oído la guerra aquí. Por supuesto, no con bombas, pero fue más una guerra psicológica [...].

Por ejemplo, no se podía trabajar, entonces la misión militar italiana se había ido, no había regresado a Italia, la habían llevado al campo de concentración ${ }^{48}$ de los

\footnotetext{
${ }^{45}$ Italia entra en la segunda guerra mundial el 10 de junio de 1940.

${ }_{46}^{46} 2012,06$ de mayo. Guayaquil (Ecuador). Archivo personal de la autora. Nerea.

${ }^{47}$ Mas específicamente sobre este argumento véase entre otros: ESTRADA, Jenny. II Guerra Mundial. Op. Cit.; FRIEDMAN, Max Paul. "Todos son peligrosos". Intervencionismo y oportunismo en la expulsión de los alemanes del Ecuador, 1941-1945. Procesos. Revista ecuatoriana de historia. Jul./Dic. 2003, n. 20, pp. 79-98; MOSCOSO, Raúl. Portadores de "civilización": la inmigración alemana a Quito. En: RAMÍREZ, Jacques (ed.). Ciudad-estado, inmigrantes y política. Quito: IAEN, 2012, pp. 121-168.

${ }^{48}$ Campo di concentramento en italiano. Cabe recordar que este dialogo de ha desarrollado en italiano. En italiano el termino campo di concentramento únicamente se utiliza para referirse al campo en el que tuvo lugar el exterminio perpetrado por los nazis.
} 
Estados Unidos, y la esposa del ministro a cargo también fue llevada al campo de concentración y era norteamericana [...]. Habían pasado [los italianos que Ecuador estaba expulsando], habían cruzado la ciudad y ella [la esposa del ministro a cargo] podía ver a su madre desde la ventanilla del tren, que por supuesto estaba todo vallado, y sólo hacer esto a su madre [gesto de saludo] y nada más. Y no, y no. Incluso eso era algo malo ${ }^{49}$.

En el caso de Nerea sea puede ver cómo la memoria y la historia tienen sus temporalidades que se entrecruzan, pero no coinciden. Las fuentes diplomáticas nos dicen que la misión militar italiana presente en el país andino entre 1922 y 1940 fue repatriada en Italia, y no enviada a un campo de concentración. En los campos de detención para los súbditos del eje de Estados Unidos, fueron enviados cinco italianos, en diciembre de 1943, que se sospechaba que estaban comprometidos con el régimen fascista.

La principal crítica que desde diversas perspectivas se dirige a la utilización de las fuentes orales en la investigación histórica es la que hace referencia a su fiabilidad, pues estas fuentes estarían sujetas a modificaciones respecto a la realidad de los hechos a causa de la subjetividad y la memoria de los testimonios. A este propósito, Paul Thompson ha matizado que todos los tipos de fuentes que los historiadores utilizan, en realidad, presentan problemáticas similares en su uso, que siempre tiene que ser cuidadoso. Así pues, no se trataría de una cuestión que concierne a las fuentes orales como tales, sino que más bien se trataría de una cuestión de método histórico ${ }^{50}$.

En nuestra opinión, en el caso de Nerea, la historia de la familia y del grupo personal se entrelaza y se superpone con la del acontecimiento y revela profundas heridas emocionales, ya que la mujer identifica la estructura del campo directamente con la del campo de concentración donde muchos judíos que no pudieron, como ella, huir de Italia vieron acabar sus vidas. Apoyándonos en los estudios sobre las mentalidades colectivas, el desfase entre las fuentes subjetivas y las escritas es útil para poner en evidencia los temores y las percepciones de Nerea y de su grupo de pertenencia en aquel momento histórico.

El segundo testimonio es el de una mujer, Rocío, descendiente de italianos que habían llegado a Ecuador en la segunda mitad del siglo XIX. En 1936, durante unas vacaciones en Italia, conoce a un soldado, se enamora de él y es correspondida. Una vez que el permiso se terminó, el hombre:

Tuvo que embarcar al final de las vacaciones, y dijo, "luego nos pondremos de acuerdo". Mamá regresó a Ecuador, yo me quedé en Italia, en casa de la hermana de mi padre. Después de un tiempo, mi madre se enfermó en Ecuador. Yo era la única hija, así que inmediatamente le envié un aviso ya que en aquel momento estaba en Alemania y le dije: "Mamá está enferma, me voy a América". Dijo: "Ve, te alcanzaré" ${ }^{51}$.

\footnotetext{
${ }^{49}$ Ibídem.

50 THOMPSON, Paul. Problemi di metodo nella storia orale. En: PASSERINI, Luisa (coord.). Storia orale. Op. cit., pp. 31-67. En este mismo trabajo, Thompson abarca también la problemática de los procesos de memorización.

${ }^{51}$ 2012, 10 de mayo. Quito (Ecuador). Archivo personal de la autora. Rocío.
} 
En 1938, el que sería su marido también se unió a ella en Ecuador. Luego la narración continúa acerca la vida en Ecuador durante la Segunda Guerra Mundial:

Durante la Segunda Guerra Mundial, el gobierno de aquí, de acuerdo con los Estados Unidos e Inglaterra, puso en la lista negra a muchos italianos, alemanes, japoneses, y mi marido también estaba allí. Y luego nos robaron todo, todo lo que teníamos. Así que fui al embajador inglés y le pregunté: "dígame por qué puso a mi marido en la lista negra”. Luego él dijo: “¿Para qué vino aquí, así, antes de la guerra? Dejó su país, su familia...". Así que dije: "Vino a casarse". Me sentí ofendida. Y dijo: "Un hombre no lo deja todo por amor". [...] Tuve que renunciar al apellido de mi marido como si fuera una madre sin estar casada porque no podía usar su apellido. Sólo usé el [...] de mi padre ${ }^{52}$.

El drama de esta historia es evidente, de las descripciones emerge toda la subjetividad, deseos y temores sufridos por la testigo. A lo largo de la conversación, de hecho, la testigo repite varias veces que su marido había llegado al Ecuador por amor; para ella este era un elemento central de su historia de vida. También dice que toda su vida pensó en las palabras del cónsul inglés y en cómo la lastimaron. La testigo acerca la situación de su marido a la de un buen número de italianos que fueron incluidos en la lista negra inglesa o americana de manera muy aleatoria, fundamentalmente en base a la nacionalidad de origen. Conforme a lo atestiguado por una importante fuente escrita, el marido de la testigo habría participado en la guerra de España, enviado por Mussolini al bando de los insurgentes ${ }^{53}$. De manera diferente, la testigo dice que después del período de permiso, el militar se había ido a Alemania. Por un lado, una cosa no excluye la otra, pero -tratando de dar un significado a la divergencia entre fuente oral y escrita- también podría ser que en el momento de la narración la testigo identificase Hitler y Franco como dos caras de la misma moneda y en todo caso ambos con muy fuertes lazos con el fascismo italiano ${ }^{54}$. En un caso similar, Alessandro Portelli nos recuerda que la fiabilidad de las fuentes orales es una "fiabilidad diferente" ya que revelan creencias y valores que de otra manera quedarían ocultos para los demás ${ }^{55}$.

Al final de la conversación, aún con el grabador encendido, Rocío quiere reconfirmar la imagen positiva que se tiene de los italianos en Ecuador y cómo esta corresponde a la realidad:

Pero los italianos aquí siempre se han comportado honorablemente. Siempre gente de trabajo. Yo no he nunca escuchado una palabra acerca de un italiano

\footnotetext{
52 2012, 10 de mayo. Quito (Ecuador). Archivo personal de la autora. Rocío.

${ }^{53}$ ESTRADA, Jenny. I/ Guerra Mundial. Op. cit.

${ }^{54}$ Cabe recordar que el testimonio de Rocío fue recopilado a distancia de mucho tiempo de los acontecimientos contados.

55 "En ciertos aspectos importantes, el interés del testimonio oral consiste no sólo en su adhesión a los hechos, sino en su divergencia con ellos: porque en esta brecha se insinúa lo imaginario, lo simbólico, el deseo. Por lo tanto, no hay fuentes orales no fiables. Una vez que se dice que deben ser examinadas críticamente como todas las demás, su diversidad consiste en que incluso las no fiables nos plantean graves problemas de interpretación histórica y estos errores insustituibles e inestimables revelan a veces cosas más importantes que dicen la verdad". PORTELLI, Alessandro. Problemi di metodo. Sulla diversità della storia orale. En: BERMANI, Cesare (coord.). Introduzione alla storia orale. Storia, conservazione delle fonti e problemi di metodo. Roma: Odradek, 1999, pp. 149-166.
} 
que haya hecho algo malo [...] siempre gente di molto lavoro ${ }^{56}$.

En cualquier caso, es importante subrayar que la idea del italiano brava gente (buen pueblo italiano) no se ha visto afectada ni siquiera en el periodo de la segunda guerra, y esto por diferentes razones. Como afirma un informante privilegiado, "Inclusive los fascistas eran tales, porque esas eran las circunstancias de la época, los deberes de la época, y luego cuando trataron de desentenderse ya era demasiado tarde" 57 .

Es sabido que hay una diferencia entre lo que fue el fascismo en casa y lo que fue el fascismo en el extranjero. Sabemos perfectamente que no tuvo un éxito comparable, excepto quizás en Brasil y en los Estados Unidos ${ }^{58}$. En cualquier caso, en Ecuador constituyó sin duda un fenómeno minoritario. Sin embargo, la mentalidad y un cierto conformismo parecen haber echado raíces. Entre otros elementos, debemos recordar cómo la misión militar italiana en el país andino entrenó a los militares ecuatorianos durante unos 20 años, coincidiendo casi totalmente con el período fascista. Además, el jefe de la Misión Militar Italiana entre 1922 y 1927 fue el General Pirzio Biroli, quien posteriormente fue General del Cuerpo Eritreo de la Guerra de Etiopía, al mando del noveno ejército italiano en Grecia, Gobernador del Gobierno Real de Montenegro y condecorado con el honor nazi de Caballero de la Gran Cruz de la Orden del Águila Alemana. Su nombre apareció en la comisión de encuesta para los supuestos criminales de guerra italianos, pero se habla poco de ello, incluso ahora, en Ecuador e Italia, porque con el fin de la guerra, la caída de Mussolini y luego la Guerra Fría con sus alianzas geopolíticas, era más aconsejable olvidarse de algunas cuestiones. Los italianos (y los inmigrantes italianos entre ellos) se convirtieron de nuevo en buenas personas, trabajadores honestos, que habían sido fascistas un poco por casualidad.

\section{Conclusiones}

En este texto se ha intentado ofrecer una reflexión acerca de la compleja relación entre historia (individual y colectiva) y memoria (esta también individual y colectiva) a partir de los estudios acerca de la inmigración italiana en Ecuador desarrollados por la autora. Se ha puesto de relieve la utilidad de las fuentes orales para recuperar informaciones no tanto acerca de los acontecimientos, como de la interpretación que tienen y han tenido para sus protagonistas. De ahí se deriva la importancia cada vez mayor que se da a esta tipología de fuente, a su producción y a su conservación en archivos orales para estudios que conciernen a las mentalidades y a la historia cultural (prevalentemente).

Se ha observado que, en Ecuador, conforme a otros casos similares, se ha afirmado una memoria de la migración del siglo XIX, de tipo apologético, que poco

\footnotetext{
${ }^{56} 2012,10$ de mayo. Quito (Ecuador). Archivo personal de la autora. Rocío.

${ }_{58} 2015,11$ de marzo, Cuenca (Ecuador). Archivo personal de la autora. Testigo anónimo.

${ }^{58}$ La documentación relativa a las secciones italianas de los fasci en el extranjero se perdió en gran parte; en el caso del Brasil, había 52 secciones en 1934 y para el caso de los Estados Unidos parece que había unas cuarenta secciones a principios de los años veinte. Para una mirada general al tema, véase FRANZINA, Emilio y SANFILIPPO, Matteo (dir.). II fascismo e gli emigranti. Roma/Bari: Laterza, 2012.
} 
tiene que ver con una memoria familiar trasmitida por los protagonistas a sus descendientes. Ahora bien, todo ello hace de contrapartida a la subjetividad, la emotividad y los desfases que existen en las narraciones de dos protagonistas que han vivido los dramáticos acontecimientos de la Segunda Guerra Mundial y que ahora son relatados a través del filtro del tiempo, y la reelaboración individual entre lo vivido, lo temido y lo deseado, en concordancia con una historia que, como es sabido, siempre se escribe en el presente. Por lo dicho, ya sea en los casos de una trasmisión de la memoria familiar, o en los relatos de los protagonistas del evento migratorio, emerge la imagen del italiano como buen y honesto trabajador.

\section{Fuentes orales}

2012, 06 de mayo. Guayaquil (Ecuador). Archivo personal de la autora. Nerea. 2012, 10 de mayo. Quito (Ecuador). Archivo personal de la autora. Rocío.

2015, 11 de marzo, Cuenca (Ecuador). Archivo personal de la autora. Testigo anónimo.

\section{Bibliografía}

ASSMAN, Jan. La memoria culturale. Scrittura, ricordo e identità politica nelle grandi civiltà antiche. Torino: Giulio Einaudi editore, 1992. [Título original en alemán: Das kulturelle Gedächtnis. Schrift, Erinnerung und politische Identität in frühen Hochkulturen. München: C. H. Beck'sche Verlagsbuchhandlung, 1992].

BLOCH, Marc. La guerra e le false notizie. Roma: Donzelli, 2004. [Títulos originales en francés: Souvenirs de guerre 1914-1915 y Réflexions d'un historien sur les fauses nouvelles de la guerre].

BURGOS, Elizabeth (con MENCHÚ, Rigoberta). Me llamo Rigoberta Menchú y así me nació la conciencia. La Habana: Casa de las Américas, 1983.

BUSTOS, Guillermo. La irrupción del testimonio en América Latina: intersecciones entre historia y memoria. Presentación del dossier: Memoria, historia y testimonio en América Latina. Historia Critica. Ene./abr. 2010, n. 40, pp. 10-19.

CONTINI, Giovanni y MARTINI, Alfredo. Verba manent. L'uso delle fonti orali per la storia contemporanea. Roma: La Nuova italia Scienifica, 1993.

ESTRADA, Jenny. // Guerra Mundial. Lista negra en Ecuador. Guayaquil: Poligrafía C.A., 2006.

FEBVRE, Lucian. Problemi di metodo storico. Torino: Einaudi, 1992, pp. 121-138. Publicación original en francés: La sensibilité et l'histoire. Comment reconstituer la vie affective d'autrefois. Annales HSS. Janv.-juin. 1941, n. 1-2, pp. 5-20.

FRANZINA, Emilio y SANFILIPPO, Matteo (dir.). II fascismo e gli emigranti. Roma/Bari: Laterza, 2012.

FRASER, Ronald. Blood of Spain. New York: Pantheon Books, 1979. [Versión en 
español: Recuérdalo tú y recuérdalo a otros. Barcelona: Editorial Critica, 1979].

FRIEDMAN, Max Paul. "Todos son peligrosos". Intervencionismo y oportunismo en la expulsión de los alemanes del Ecuador, 1941-1945. Procesos. Revista ecuatoriana de historia. Jul./Dic. 2003, n. 20, pp. 79-98.

GINZBURG, Carlo. II formaggio e i vermi. II cosmo di un mugnaio del '500. Torino: Einaudi, 1976. [Trad. en español: El queso y los gusanos. El cosmos, según un molinero del siglo XVI. Barcelona: Muchnik Editores, S.A., 1981].

GINZBURG, Carlo. II filo e le tracce: vero, falso, finto. Milano: Feltrinelli, 2006, pp. 208-209. [Trad. en español: El hilo y las huellas: Lo verdadero, lo falso, lo ficticio. Buenos Aires: Fondo de Cultura Economica, 2010].

GINZBURG, Carlo. II giudice e lo storico. Considerazioni in margine al processo Sofri. Milano: Feltrinelli, 2006. [Versión en español: El juez y el historiador. Consideraciones al margen del proceso Sofri. Madrid: Anaya \& Mario Muchnik, 1993].

GINZBURG Carlo. El vinculo de la vergüenza. New Left Review. Ene./feb. 2020, n. 120, pp. 39-48.

HALBAWCHS, Maurice. Los marcos sociales de la memoria. Barcelona: Anthropos Editorial, 2004. [Original en francés: Les cadres sociaux de la mémoire. París: Félix Alcan, 1925].

JOUTARD, Philippe. Le voci del passato. Torino: SEI, 1987. [Original en francés: Ces voix qui nous viennent de passè. París: Hachette, 1983].

LEVI, Primo. Se questo è un uomo. Torino: De Silva, 1947.

LEVI, Primo. I sommersi e i salvati. Torino: Einaudi, 1986.

MOSCOSO, Raúl. Portadores de "civilización": la inmigración alemana a Quito. En: RAMÍREZ, Jacques (ed.). Ciudad-estado, inmigrantes y política. Quito: IAEN, 2012, pp. 121-168.

NOIRIEL, Gérard. Penser avec, penser contre. Itinéraire d'un historien. París: Éditions BELIN, 2003.

PAGNOTTA, Chiara. La migración ecuatoriana e España e Italia. Historias, memorias e identidades 1995-2007. Quito: Universidad Andina Simón Bolívar; Corporación Editora Nacional, 2014.

PAGNOTTA, Chiara. Situando los márgenes de la nación. Los italianos en Ecuador (XIX-XX). Quito: Abya-Yala; TEIAA, 2016.

PAGNOTTA, Chiara y OLIVEIRA DE ASSIS, Glaucia. Os italianos no espaço público de Santa Catarina (Brasil). Entre epopeia e festas étnicas. Confluenze [em 
línea]. 2017, vol. 9, n. 1, pp. 78-106. Disponible en $<$ https://confluenze.unibo.it/article/view/7078/6805>.

PASSERINI, Luisa. Conoscenza storica e storia orale. Sull'utilità e il danno delle fonti orali per la storia. En: PASSERINI, Luisa (coord.). Storia orale: vita quotidiana e cultura materiale delle classi subalterne. Torino: Rosenberg \& Sellier, 1978, pp. VII-XLIII.

PASSERINI, Luisa. Storia e soggettività. Le fonti orali, la memoria. Firenze: la Nuova Italia Editrice, 1988.

PAVONE, Claudio. Una guerra civile. Saggio storico sulla moralità nella resistenza. Torino: Bollati Boringhieri, 1994.

PORTELLI, Alessandro. La orden ya fue ejecutada. México: Fondo de Cultura Económica, 2003. [Original en italiano: L'ordine è già stato eseguito. Roma, le Fosse Ardeatine, la memoria. Roma: Donzelli, 1999].

PORTELLI, Alessandro. Problemi di metodo. Sulla diversità della storia orale. En: BERMANI, Cesare (coord.). Introduzione alla storia orale. Storia, conservazione delle fonti e problemi di metodo. Roma: Odradek, 1999, pp. 149-166.

PORTELLI, Alessandro. Racconti di cura, racconti di guerra. La legittimità della narrazione. Genesis. Rivista della società italiana delle storiche. 2002, vol. I, n. 1, pp. 254-259.

PROSPERI, Adriano. La vocazione. Storie di gesuiti tra Cinquecento e Seicento: Torino: Einaudi, 2016.

RENAN, Ernst. Qu'est-ce qu'une nation? En: FOREST, Philippe (dir.). Qu'est-ce qu'une nation? Lit-térature et identité nationale de 1871 à 1914. París: Pierre Bordas et fils, Éditeur, 1991, pp. 12-48.

RICOEUR, Paul. La memoria, la historia el olvido. Buenos Aires: Fondo de Cultura Económica de Argentina, 2000. [Original en francés: La mémoire, l'histoire, l'oubli. Paris: Editions de Seuil, 2000].

ROSENWEIN, Barbara. Worrying about Emotions in History. The American Historical Review. 2002, vol. 107, n. 3, pp. 821-841.

SCARZANELLA, Eugenia. Italiani malagente. Immigrazione, criminalità, razzismo in Argentina, 1890-1940. Milano: Franco Angeli, 1999. [En español: Ni gringos ni indios. inmigración, criminalidad y racismo en Argentina. Buenos Aires: Universidad de Quilmes, 2002].

THOMPSON, Paul. Problemi di metodo nella storia orale. En: PASSERINI, Luisa (coord.). Storia orale: vita quotidiana e cultura materiale delle classi subalterne. Torino: Rosenberg \& Sellier, 1978, pp. 31-67. 
TRAVERSO, Enzo. El pasado. Instrucciones de uso. Historia, memoria, política. Madrid; Barcelona: Marcial Pons; Ediciones Jurídicas y Sociales, S.A., 2007.

VANGELISTA, Chiara. Da fala á história: notas em torno da legitimidade da fonte oral. En: HERCULANO LOPES, Antonio; PIMIENTA VELLOSO, Monica y JATAHY PESAVENTO, Sandra (orgs.). História e linguagens. Texto, imagem, oralidade e representaçoes. Rio de Janeiro: 7Letras, 2006, pp. 185-193.

WIEVIORKA, Annette. L'era del testimone. Milano: Raffaello Cortina Editore, 1999. [Original en francés: L'Ėre de témoin. París: Plon, 1998].

X, Malcolm y HALEY, Alex. The autobiography of Malcolm X. New York: Grove Press, Inc., 1965. 